\title{
Rock Mass Quality Evaluation Based on Unascertained Measure and Intuitionistic Fuzzy Sets
}

\author{
Shuliang $W u\left(\mathbb{D},{ }^{1,2,3}\right.$ Xidong $D{ }^{1,2}$ and Shan Yang $\mathbb{D}^{3}$ \\ ${ }^{1}$ State Key Laboratory of Nuclear Resources and Environment, East China University of Technology, Nanchang 330013, China \\ ${ }^{2}$ School of Earth Sciences, East China University of Technology, Nanchang 330013, China \\ ${ }^{3}$ School of Resources and Safety Engineering, Central South University, Changsha 410083, China
}

Correspondence should be addressed to Shuliang Wu; 616761400@qq.com

Received 3 December 2019; Revised 17 February 2020; Accepted 23 March 2020; Published 27 April 2020

Academic Editor: Harish Garg

Copyright (@) 2020 Shuliang Wu et al. This is an open access article distributed under the Creative Commons Attribution License, which permits unrestricted use, distribution, and reproduction in any medium, provided the original work is properly cited.

Evaluation of rock mass quality is of great significance to the design and construction of geotechnical engineering. In order to evaluate the quality of engineering rock mass scientifically and deal with the fuzzy information in the rock mass quality evaluation reasonably, a model for evaluation of rock mass quality based on unascertained measure and intuitionistic fuzzy sets (UM-IFS) was proposed. First, the membership of rock mass quality evaluation index was determined by the single index measure function of unascertained measure (UM) theory. Based on the intuitionistic fuzzy sets (IFS) theory, the single index measure evaluation matrix based on IFS (IFS-single index measure evaluation matrix) was obtained. By synthesizing various subjective and objective weighting methods, the range of index weight was determined, and the index weight vector based on IFS (IFS-index weight vector) was constructed. Then, the IFS-single index measure evaluation matrix and the IFS-index weight vector were used to calculate the scores of rock mass samples and evaluate rock mass quality. Finally, fuzzy analysis was performed on the weight of rock mass quality evaluation index. The established model for evaluation of rock mass quality was applied to the underground engineering rock mass in Guangzhou pumped storage power plant, and the evaluation results were compared with the other 4 effective models for rock mass quality evaluation. The results show that rock mass quality evaluation based on UM-IFS is consistent with the actual situation, and the fuzziness of evaluation index weight has no obvious correlation with its value.

\section{Introduction}

In every stage of geotechnical engineering design and construction, it is necessary to classify the rock mass quality correctly and economically for supporting design and safe construction of geotechnical engineering $[1,2]$. Therefore, an accurate and objective method for engineering rock mass evaluation is of great significance to engineering construction.

Over the past decades, research on rock mass evaluation has gained enormous attention. In 1907, the Former Soviet scholar Protogyakonov put forward the Protodyakonov coefficient method [3], which divides the rock mass into 10 grades according to the Protodyakonov solid coefficient $f$. The shortcoming of this method is that it cannot fully reflect the various factors that determine the characteristics of rock mass. American scholar Deer proposed the rock mass quality classification method in 1967, which divides rock mass into 5 grades according to the rock mass quality index RQD [4]. At present, many methods for classification of rock mass quality still regard it as a basic index. American scholar Wickham proposed the rock structure rank method (RSR) [5] in 1972. South African engineer Bieniawski proposed rock mass geomechanical classification (RMR) [6] in 1973; the RMR of rock mass can be divided into 5 grades according to 5 indexes of rock mass strength, RQD, joint spacing, joint condition, and groundwater. In 1974, Norwegian engineer Barton proposed the $Q$ [7] for rock mass classification. The above methods for classification of rock mass quality are widely used and influential in the world. The study of rock mass quality classification in China began after 1970, and the Protogyakonov coefficient method has been used until then. 
With the shortcomings of Protogyakonov coefficient exposed, various new methods for classification of rock mass quality have begun to emerge. In 1979, Gu and Huang [8] put forward a method of coefficient $Z$ for rock mass quality classification. In 1997, Sun et al. [9] put forward the CSMR method based on $R M R$ system modification.

With the deepening of the study on rock mass characteristics, researchers have realized that the engineering geological characteristics of rock mass depend on the interaction of various factors $[10,11]$. These factors $[12,13]$ mainly include the properties of rock materials, the mechanical properties of rock discontinuity structural plane, the structural types of rock mass, the influence of water, and the conditions of in situ stress. Therefore, the comprehensive effect of various factors should be fully taken into account when classifying engineering rock mass $[14,15]$. In recent years, many new theoretical methods have been introduced into evaluation of rock mass quality and have been well applied in a large number of projects. Therefore, the evaluation of rock mass quality has developed from the earliest single factor analysis and evaluation to the direction of multifactor comprehensive evaluation. Fattahi et al. [16] used the fuzzy hierarchy process to evaluate the quality of surrounding rock in the excavation damage area. Rezaei and Monjezi [17] used the intelligent method based on the fuzzy model to predict unconfined compressive strength of surrounding rock, which has theoretical guiding significance for the evaluation of rock mass quality. Wu et al. [18] proposed a method for classification of rock mass quality based on MCS-TOPSIS, which used the combination weighting method to determine the index weight. Other methods include entropy weight-extension model [19], weighted Mahalanobis distance discriminant analysis model [20], and fractal dimension model [21]. These methods promote the development of research on rock mass quality classification, but there are also some shortcomings: (1) the evaluation of rock mass quality based on multi-index often needs to determine the index weight, the subjective weighting method has subjective randomness, and the objective weighting method has poor generality. In addition, the index weights obtained by various weighting methods are inconsistent and difficult to compare. Therefore, the determination of index weight is an important issue in rock mass quality evaluation. (2) The index of rock mass quality evaluation has fuzziness and uncertainty. How to quantify the index value reasonably is also a problem that needs further optimization in rock mass quality evaluation. In view of the above 2 points, this work constructs a model for rock mass quality evaluation in Section 2.3, which can effectively quantify the indexes of rock mass quality evaluation, and the process of weighting is more reasonable. Moreover, the example checking calculation is carried out in Section 3.2.

The intuitionistic fuzzy sets (IFS) proposed by Atanassov [22] have attracted great attention of scholars in related fields and have been applied in many fields such as decisionmaking [23], prediction, and machine learning. The improved IFS proposed by Garg [24, 25] reduce the loss of useful information and make the decision-making process more reasonable. In addition, there are multiple counterparts for the manifestation of fuzzy evaluation information. The Pythagorean fuzzy sets $[26,27]$ based on the extension of IFS satisfy that the sum of membership and nonmembership is greater than 1 , which makes it possible to make decisions without modifying intuitionistic fuzzy decision value, but its integration operator is relatively complex. Proportional hesitant fuzzy linguistic term set [28] and proportional interval type-2 hesitant fuzzy set [29] allow decision-makers to evaluate an attribute in several possible language terms and allow performing linguistic distribution assessments, which are more suitable for linguistic group decision-making. On the whole, IFS are universal and applicable, which can meet the general needs of many kinds of evaluation, and the expression of fuzzy information is clear. In order to satisfy the expression of fuzzy information and improve the efficiency in evaluation of rock mass quality as much as possible, this work introduces the theory of unascertained measure (UM) [30] into IFS, improves the calculation method for membership of IFS, and proposes a model for evaluation of rock mass quality based on unascertained measure and intuitionistic fuzzy set (UM-IFS). First, the membership of evaluation index is calculated by $\mathrm{UM}$, and then, the weight of evaluation index is calculated by various subjective and objective weighting methods; the range of index weight is determined and converts it to the index weight based on IFS (IFS-index weight). Finally, the established model is applied to evaluation of engineering rock mass quality to verify the feasibility and sensitivity analysis on weight of evaluation index.

The remainder of this paper is organized as follows. Section 2 establishes the model for evaluation of rock mass quality based on UM-IFS. Section 3 takes the underground engineering rock mass of Guangzhou pumped storage power plant as an example to test the validity of our work. Finally, Section 4 concludes our work and offers directions for the future research.

\section{Model for Evaluation of Rock Mass Quality}

2.1. Theory of Intuitionistic Fuzzy Sets (IFS). The theory of intuitionistic fuzzy sets (IFS) [31] is a theory of uncertain information analysis based on membership, nonmembership, and hesitancy degree. It has more flexible ability to deal with fuzzy information than traditional fuzzy sets [32].

Suppose a universe $X$, which contains two mappings $m_{A}$ : $X \longrightarrow[0,1]$ and $n_{A}: X \longrightarrow[0,1] ;$ an IFS $A$ is expressed as

$$
A=\{\langle x, m A(x), n A(x)\rangle \mid x \in X\}
$$

where $m_{A}(x)$ and $n_{A}(x)$ are the membership and nonmembership of $A$. The numbers $m_{A}(x)$ and $n_{A}(x)$ describe, respectively, the degree of belonging and rejection of $x \in X$ in $A$, where

$$
\begin{aligned}
m A(x) & \in[0,1], \\
n A(x) & \in[0,1], \\
0 & \leq m A(x)+n A(x) \leq 1 .
\end{aligned}
$$

For convenience, an IFS $A$ is expressed as $\langle m, n\rangle$. 
IFS also have a attribute parameter hesitancy degree $t_{A}(x)=1-m_{A}(x)-n_{A}(x)$; the number $t_{A}(x)$ describes the uncertainty of belonging of $x \in X$ in $A$.

In particular, if $m_{A}(x)=1-n_{A}(x)$, then IFS $A$ degenerates to general fuzzy set; if $m_{A}(x)=0, n_{A}(x)=1$ or $m_{A}(x)=1$, $n_{A}(x)=0$; then, the information of $x$ is accurate. Therefore, IFS are the extension of fuzzy set.

According to the definition of IFS, its geometric interpretation is as follows:

Suppose a universe $X$ and its subset $Y$ on the Euclidean plane in Cartesian coordinates. For an IFS $A$ on $X$, construct a function $f_{A}: X \longrightarrow Y$ such that $p=f_{A}(x) \in Y, \forall x \in X$, and the coordinates of point $p$ are $\langle m A(x), n A(x)\rangle$.

The geometric meaning of IFS is shown in Figure 1.

The equality for calculating the score $M(x)$ of $x$ is

$$
M(x)=m A(x)-n A(x), \quad M(x) \in[-1,1] .
$$

The equalities for calculating the sum and product of two IFS $A$ and $B$ are as follows:

$$
\begin{aligned}
A+B= & \{\langle x, m A(x)+m B(x)-m A(x) m B(x), n A(x) n B \\
& \cdot(x)\rangle \mid x \in X\}, \\
A \cdot B= & \{\langle x, m A(x) m B(x), n A(x)+n B(x) \\
& -n A(x) n B(x)\rangle \mid x \in X\} .
\end{aligned}
$$

2.2. Theory of Unascertained Measure (UM). The theory of unascertained measure (UM) and its mathematical processing was first put forward by Wang [33] in 1990. On this basis, Liu et al. [34, 35] established the unascertained mathematical theory and applied it to decision-making problems. Unascertained information is a new kind of uncertainty information which is different from fuzzy information, random information, and grey information. Compared with other evaluation methods, the UM evaluation method has the advantages of nonnegativity, normalization, and additivity, which also ensures the order of evaluation space. The theory of UM uses single index measure function [36] to calculate the single index measure value of sample index and evaluates the sample comprehensively.

Assuming that the sample set $R$ of rock mass quality evaluation has $p$ samples, these samples $R_{i}$ are described by $Q$ indexes, i.e., index set $O=\left\{O_{1}, O_{2}, \ldots, O_{q}, \ldots, O_{Q}\right\}$ and $R_{i}=\left\{o_{i 1}, o_{i 2}, \ldots, o_{i Q}\right\}$, where $o_{i j}(i=1,2,3, \ldots, p ; j=1,2,3, \ldots$, Q) is the index value of sample $R_{i}$.

As sample $R_{i}$ and index $O_{i}$ have $C_{1}, C_{2}, \ldots, C g$ evaluation grades, the evaluation grade set is $C=\left\{C_{1}, C_{2}, \ldots, C_{g}\right\}$, and any 2 evaluation grades are independent of each other. If the corresponding value of each evaluation grade is increasing or decreasing in turn, that is, $C_{1}>C_{2}>\cdots>C_{g}$ or $C_{1}<C_{2}<\cdots<C_{g}$, then $\left\{C_{1}, C_{2}, \ldots, C_{g}\right\}$ is the ordered division class on evaluation grade set $C$, and the meaning of the ordered space of evaluation grade is that the latter grade is higher (or lower) than the standard of the previous grade.

The single index measure value $\mu_{i j k}=\mu\left(o_{i j} \in C_{k}\right)$ of sample $R_{i}$ indicates the degree to which the index value $o_{i j}$ of sample

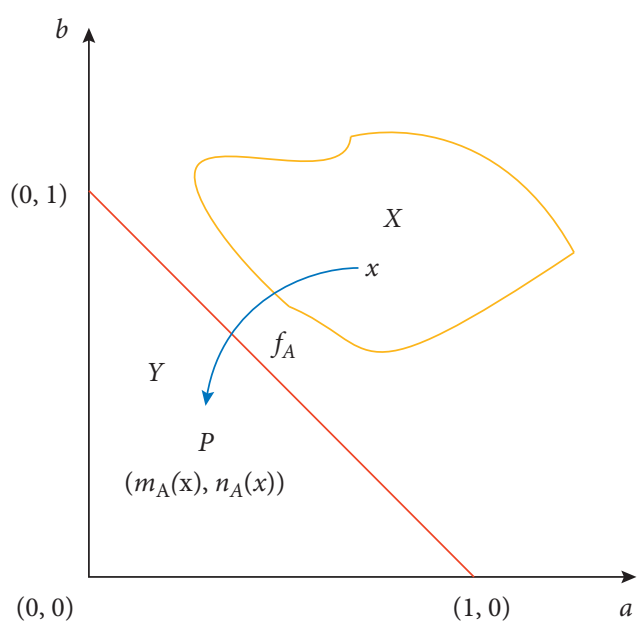

Figure 1: Geometric meaning of IFS.

belongs to the $k$-th grade. According to the index value $o_{i j}$ of sample $R_{i}$, the corresponding single measure value $\mu_{i j k}$ can be obtained by the single index measure function $u$. In the construction of single index measure function, the function categories that can be selected are linear type, exponential type, sinusoidal type, etc. Among them, linear function is the most widely used. Therefore, the linear function is used to calculate the single index measure value. The expression of the single index measure function $\mu$ corresponding to the index value $o_{i j}$ on the interval $\left[a_{i}, a_{i+1}\right]$ is as follows:

$$
\begin{gathered}
\mu_{i}\left(o_{i j}\right)= \begin{cases}\frac{-o_{i j}}{a_{i+1}-a_{i}}+\frac{a_{i+1}}{a_{i+1}-a_{i}}, & a_{i} \leq o_{i j} \leq a_{i+1}, \\
0, & o_{i j} \geq a_{i+1},\end{cases} \\
\mu_{i+1}\left(o_{i j}\right)= \begin{cases}0, & o_{i j} \leq a_{i}, \\
\frac{o_{i j}}{a_{i+1}-a_{i}}-\frac{a_{i}}{a_{i+1}-a_{i}}, & a_{i} \leq o_{i j} \leq a_{i+1} .\end{cases}
\end{gathered}
$$

The single index measure value satisfies the following conditions:

$$
\begin{aligned}
& 0 \leq \mu\left(o_{i j} \in C_{k}\right) \leq 1, \\
& \sum_{k=1}^{g} \mu\left(o_{i j} \in C_{k}\right)=1, \\
& \mu\left[o_{i j} \in \bigcup_{l=1}^{k} C_{l}\right]=\sum_{l=1}^{k} \mu\left(o_{i j} \in C_{l}\right),
\end{aligned}
$$

where equation (8) is called single index measure value $\mu$ satisfying "normalization" for evaluation set $C$; equation (9) is called single index measure value $\mu$ satisfying "additivity" for evaluation set $C$.

Therefore, the single index measure value is to construct the function $u$ of each index according to the definition of the $\mathrm{UM}$, and then, the index value $o_{i j}$ of sample $R_{i}$ is introduced into the function $u$ to obtain the real number 
between $[0,1]$, which is the UM describing that $o_{i j}$ belongs to $C_{k}$.

The matrix of all single index measure values $\mu_{i j k}$ of sample $R_{i}$ is as follows:

$$
\left(\mu_{i}\right)_{\mathrm{Q} \times g}=\left[\begin{array}{cccc}
\mu_{i 11} & \mu_{i 12} & \cdots & \mu_{i 1 g} \\
\mu_{i 21} & \mu_{i 22} & \cdots & \mu_{i 2 g} \\
\vdots & \vdots & \ddots & \vdots \\
\mu_{i \mathrm{Q} 1} & \mu_{i \mathrm{Q} 2} & \cdots & \mu_{i \mathrm{Q} g}
\end{array}\right],
$$

where equation (10) is called the single index measure evaluation matrix of sample $R_{i}$.

\subsection{Evaluation of Rock Mass Quality Based on UM-IFS.} In order to solve the problem of fuzzy expression of index value, a method for fuzzy expression of index value based on UM-IFS is proposed. Using the single index measure function, the single index measure value is calculated according to the index value and expressed by IFS; thus, the single index measure value based on IFS $\left\langle\mu_{i j k}, v_{i j k}\right\rangle$ is obtained, which is called IFS-single index measure value. For quantitative indexes, the hesitancy degree is 0 ; for qualitative indexes, a certain hesitancy degree can be given according to experience knowledge and engineering practice to improve the fuzzy expression ability of the model. Generally, it can be taken as 0.2 .

The matrix of all IFS-single index measure values of sample $R_{i}$ is as follows:

$$
\left(F_{i}\right)_{\mathrm{Q} \times g}=\left[\begin{array}{cccc}
\left\langle\mu_{i 11}, v_{i 11}\right\rangle & \left\langle\mu_{i 12}, v_{i 12}\right\rangle & \cdots & \left\langle\mu_{i 1 g}, v_{i 1 g}\right\rangle \\
\left\langle\mu_{i 21}, v_{i 21}\right\rangle & \left\langle\mu_{i 22}, v_{i 22}\right\rangle & \cdots & \left\langle\mu_{i 2 g}, v_{i 2 g}\right\rangle \\
\vdots & \vdots & \ddots & \vdots \\
\left\langle\mu_{i \mathrm{Q} 1}, v_{i q 1}\right\rangle & \left\langle\mu_{i \mathrm{Q} 2}, v_{i q 2}\right\rangle & \cdots & \left\langle\mu_{i \mathrm{Q} g}, v_{i \mathrm{Q} g}\right\rangle
\end{array}\right] .
$$

The single index measure evaluation matrix based on IFS is called IFS-single index measure evaluation matrix of sample $R_{i}$.

The weight of rock mass quality evaluation index is fuzzy. In order to obtain objective and reasonable index weight, various subjective and objective weighting methods are considered and used to calculate index weight, so that the range of index weight is determined and expressed by IFS. If the maximum value in the weight interval of an index is $1-\tau_{q}$ and the minimum value is $\rho_{q}$, the index weight based on IFS (IFS-index weight) is expressed as $w_{q}=\left\langle\rho_{q}, \tau_{q}\right\rangle$. All the IFSindex weights constitute the IFS-index weight vector $W$.

According to the IFS-index weight vector $W$ and the IFSsingle index measure evaluation matrix, the comprehensive mean value $S_{i k}$ of each grade of the sample $R_{i}$ is calculated, and the corresponding score $M_{i}\left(S_{i k}\right)$ is obtained by using equation (2). By sorting the scores $M_{i}\left(S_{i k}\right)$, the corresponding grade of the maximum value is the grade of the sample $R_{i}$. The equalities for comprehensive mean value $S_{i k}$ of samples $R_{i}$ are as follows:

$$
\begin{aligned}
S_{i k} & =\sum_{q=1}^{Q} \bar{F}_{i q k}, \\
\bar{F}_{i q k} & =\left\langle\bar{\mu}_{i q k}, \bar{v}_{i q k}\right\rangle=w_{q} F_{i q k}=\left\langle\rho_{q} \mu_{i q k}, \tau_{q}+v_{i q k}-\tau_{q} v_{i q k}\right\rangle,
\end{aligned}
$$

where $\bar{F}_{i q k}$ in equation (13) is the weighted IFS-single index measure value.

2.4. Fuzzy Analysis for Weight of Rock Mass Quality Evaluation Index. Index weight directly affects the result of rock mass quality evaluation. The weight of rock mass quality evaluation index is analyzed by IFS. Assuming that other conditions remain unchanged, the weight $w_{q}=\left\langle\rho_{q}, \tau_{q}\right\rangle$ of index $O_{q}$ becomes $w_{q}^{\prime}=\left\langle\rho_{q}+\Delta \rho_{q}, \tau_{q}+\Delta \tau_{q}\right\rangle$ and the evaluation result $C_{k-1}>C_{k}>C_{k+1}$ remains unchanged; the IFSindex weight satisfies the following conditions:

$$
\left\{\begin{array}{l}
M_{i}\left(S_{i(k-1)}\right)>M_{i}\left(S_{i k}\right), \\
M_{i}\left(S_{i k}\right)>M_{i}\left(S_{i(k+1)}\right), \\
0 \leq \rho_{q}+\Delta \rho_{q}+\tau_{q}+\Delta \tau_{q} \leq 1, \\
0 \leq \rho_{q}+\Delta \rho_{q} \leq 1-\tau_{q}, \\
0 \leq \tau_{q}+\Delta \tau_{q} \leq 1-\rho_{q},
\end{array}\right.
$$

The range of parameters $\Delta \rho$ and $\Delta \tau$ reflects the fuzziness of index weight, and the sensitivity of index weight changes. According to the range of $\Delta \rho$ and $\Delta \tau$, the fuzzy value $\zeta_{i q}$ of index weight $O_{q}$ of sample $R_{i}$ is as follows:

$$
\zeta_{i q}=\frac{H_{i q}}{H_{q}},
$$

where $H_{i q}$ in equation (15) is the area determined by inequality group (14) and $H_{q}$ in equation (15) is the area determined by the following 3 inequalities in inequality group (14).

\section{Application of the Model for Evaluation of Rock Mass Quality}

3.1. Engineering Overview. In this paper, the underground engineering rock mass of Guangzhou pumped storage power plant is selected as an engineering case for modeling [37]. Guangzhou pumped storage power plant is the second largest installed capacity in the world and covers an area of $27 \mathrm{~km}^{2}$. The power station was started in May 1989 and completed in March 2000. Guangzhou pumped storage power plant is located in the deep valley of Lvtian Town, Conghua District, Guangzhou City, on the north side of Nankun Mountains. It is $100 \mathrm{~km}$ away from Guangzhou. The geographical location of the power plant is shown in Figure 2.

Many underground buildings of Guangzhou pumped storage power plant, such as the underground power house and the diversion tunnel, are located in the medium coarse 


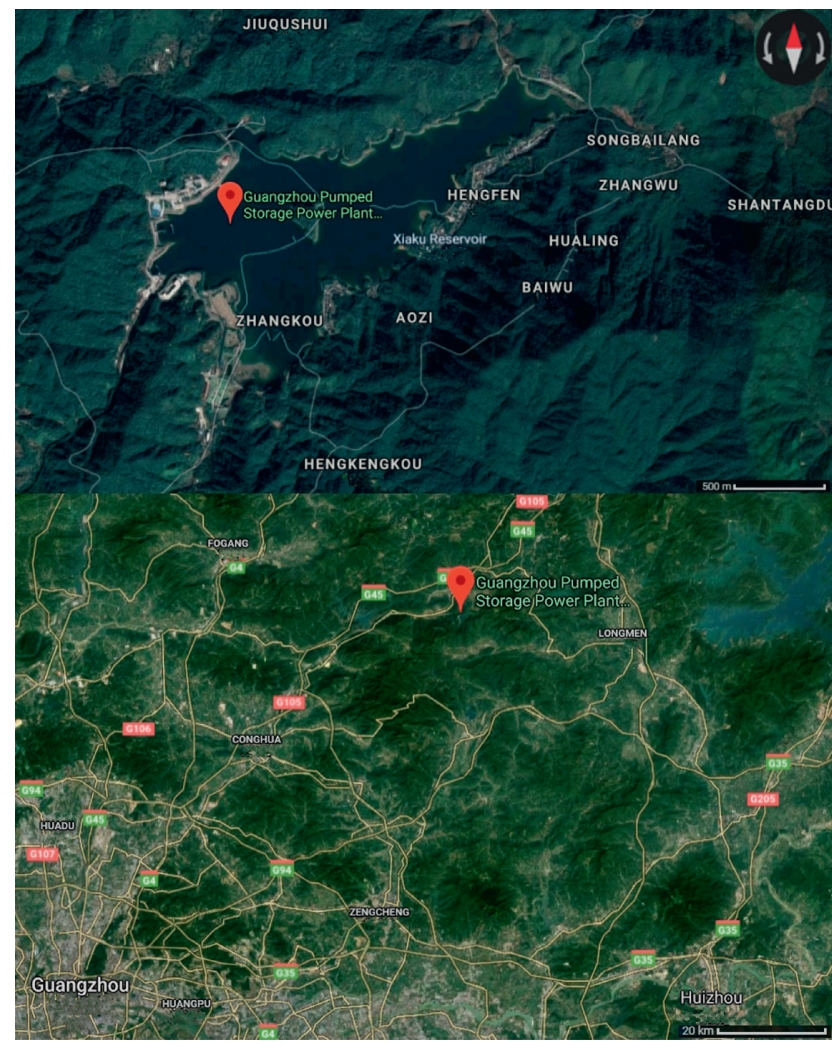

Figure 2: Geographical location map of Guangzhou pumped storage power plant.

grained biotite granite of Yanshan period. Because of geological process, the granite in this area forms alteration zones such as montmorillonite, hydrodolomitization, kaolinization, chloritization, and carbonation. In particular, montmorillonite is the most serious. However, because the alteration zone is formed from the bottom to the top and from the inside to the outside, it still has considerable strength in the closed state, so the timely closure after excavation will maintain the stability of surrounding rock. As rock discontinuity persistence is one of the very important influential factors on the rock mass quality [38], it is difficult to measure it in rock mass engineering [39]. At the same time, the coefficient of weathering, fissure coefficient, joint, and other indexes can reflect the influence of structure of rock mass and rock discontinuity structural plane on rock mass quality to a certain extent. Therefore, according to the geological data of the project and the existing research results [40], considering the correlation between indexes and the difficulty of obtaining index data, rock quality designation (RQD), uniaxial saturated compressive strength of rock $\left(R_{\mathrm{W}}\right)$, fissure coefficient $\left(K_{\mathrm{v}}\right)$, coefficient of weathering $\left(K_{\mathrm{f}}\right)$, and groundwater seepage $(w)$ are selected as the indexes of the rock mass quality evaluation. 8 groups of sample data were selected from the weathering alteration zones with different weathering corrosion degrees for evaluation and are shown in Table 1.

According to Specification for design of hydraulic tunnel and the classification standards provided by the project [42], the quality of rock mass of the project is divided into 5 grades. The specific evaluation standards are shown in Table 2.

3.2. Data Standardization. According to the standard of underground engineering rock mass quality evaluation, the index data of 8 rock samples are analyzed preliminarily. Because of the different dimension of indexes, the extreme value method is used to normalize the index value [31]. The forward evaluation index $o_{i j}$ of rock mass $R_{i}$ is disposed by using equation (16), and the reverse evaluation index $o_{i j}$ of rock mass $R_{i}$ is disposed by using equation (17), which are as follows:

$$
\begin{aligned}
& o_{i j}^{\prime}=\frac{o_{i j}-\min _{j}\left(o_{i j}\right)}{\max _{j}\left(o_{i j}\right)-\min _{j}\left(o_{i j}\right)}, \\
& o_{i j}^{\prime}=\frac{\max _{j}\left(o_{i j}\right)-o_{i j}}{\max _{j}\left(o_{i j}\right)-\min _{j}\left(o_{i j}\right)} .
\end{aligned}
$$

The normalized data are shown in Table 3 and Figure 3.

From Figure 3, the distribution of index values of samples is discrete, and there is no regularity among the index values of each sample. The indexes values of any sample are distributed in different grades, so it is impossible to evaluate the rock mass quality of the sample directly according to the index value. Therefore, these samples can be used to test the validity of the model.

\subsection{Evaluation of Rock Mass Quality}

3.3.1. Single Index Measure Function of Index of Rock Mass Quality Evaluation. According to the theory of UM and evaluation standard in Table 2, the single index measure functions of the 5 indexes obtained by equations (5)-(9) are shown in Figure 4.

3.3.2. IFS-Single Index Measure Evaluation Matrix. Taking sample 1 in Table 3 as an example, according to the 5 index values of sample 1 and using the single index measure function in Figure 4, the single index measure evaluation matrix of sample 1 is calculated as follows:

$$
\left(\mu_{1 j k}\right)_{5 \times 5}=\left[\begin{array}{ccccc}
0.00 & 0.00 & 0.00 & 0.08 & 0.92 \\
0.00 & 0.00 & 0.60 & 0.40 & 0.00 \\
0.00 & 0.00 & 0.00 & 0.40 & 0.60 \\
0.00 & 0.00 & 0.25 & 0.75 & 0.00 \\
1.00 & 0.00 & 0.00 & 0.00 & 0.00
\end{array}\right]
$$

According to the definition of IFS, the single index measure evaluation matrix is transformed into IFS-single index measure evaluation matrix. As the 5 indexes of rock mass quality evaluation are quantitative indexes, the hesitancy degree of IFS-single index measure value is 0 .

The IFS-single index measure evaluation matrix of sample 1 is as follows: 
TABLE 1: Rock mass data of the underground engineering in Guangzhou pumped storage power plant [41].

\begin{tabular}{|c|c|c|c|c|c|c|c|}
\hline Sample & Footage $(\mathrm{m})$ & Weathering corrosion & RQD (\%) & $R_{\mathrm{W}}(\mathrm{MPa})$ & $K_{\mathrm{v}}$ & $K_{\mathrm{f}}$ & $w\left[\mathrm{~L} \cdot(\min \cdot 10 \mathrm{~m})^{-1}\right]$ \\
\hline 1 & \multirow{2}{*}{$0+000 \sim 0+067$} & \multirow{2}{*}{ Fault alteration zone of medium to weak weathering } & 26 & 36 & 0.22 & 0.35 & 5 \\
\hline 2 & & & 50 & 40.2 & 0.5 & 0.5 & 10 \\
\hline 3 & \multirow{2}{*}{$0+067 \sim 0+130$} & \multirow{2}{*}{ Weak weathered } & 52 & 25 & 0.2 & 0.5 & 5 \\
\hline 4 & & & 71 & 90 & 0.35 & 0.3 & 18 \\
\hline 5 & \multirow{2}{*}{$0+130 \sim 0+198$} & \multirow{2}{*}{ Slightly weathered } & 75 & 95 & 0.7 & 0.5 & 0 \\
\hline 6 & & & 77.5 & 90 & 0.57 & 0.45 & 10 \\
\hline 7 & \multirow{2}{*}{$0+198 \sim 0+297$} & \multirow{2}{*}{ Fault alteration zone } & 50 & 70 & 0.5 & 0.25 & 5 \\
\hline 8 & & & 50.9 & 34 & 0.32 & 0.35 & 21 \\
\hline
\end{tabular}

TABLE 2: Standard of underground engineering rock mass quality evaluation.

\begin{tabular}{lccccc}
\hline Grades & RQD $(\%)$ & $R_{\mathrm{W}}(\mathrm{MPa})$ & $K_{\mathrm{v}}$ & $K_{\mathrm{f}}$ & $w\left[\mathrm{~L} \cdot(\mathrm{min} \cdot 10 \mathrm{~m})^{-1}\right]$ \\
\hline I (stability) & $>90$ & $>120$ & $>0.75$ & $>0.8$ & $<5$ \\
II (basic stability) & $75 \sim 90$ & $60 \sim 120$ & $0.45 \sim 0.75$ & $0.6 \sim 0.8$ & $5 \sim 10$ \\
III (poor stability) & $50 \sim 75$ & $30 \sim 60$ & $0.3 \sim 0.45$ & $0.4 \sim 0.6$ & $10 \sim 25$ \\
IV (instability) & $25 \sim 50$ & $15 \sim 30$ & $0.2 \sim 0.3$ & $0.2 \sim 0.4$ & $25 \sim 125$ \\
V (extremely instability) & $<25$ & $<15$ & $<0.2$ & $<0.2$ & $>125$ \\
\hline
\end{tabular}

TABLE 3: Normalized values of rock mass quality indexes.

\begin{tabular}{lccccc}
\hline Sample & RQD $(\%)$ & $R_{\mathrm{W}}(\mathrm{MPa})$ & $K_{\mathrm{v}}$ & $K_{\mathrm{f}}$ & $w\left[\mathrm{~L} \cdot(\mathrm{min} \cdot 10 \mathrm{~m})^{-1}\right]$ \\
\hline I-II & 1.000 & 1.000 & 1.000 & 1.000 & 0.960 \\
II-III & 0.769 & 0.429 & 0.455 & 0.667 & 0.920 \\
III-IV & 0.385 & 0.143 & 0.182 & 0.333 & 0.800 \\
IV-V & 0.000 & 0.000 & 0.000 & 0.000 & 0.000 \\
1 & 0.015 & 0.240 & 0.036 & 0.250 & 0.960 \\
2 & 0.385 & 0.095 & 0.545 & 0.500 & 0.920 \\
3 & 0.415 & 0.714 & 0.000 & 0.500 & 0.167 \\
4 & 0.708 & 0.762 & 0.273 & 0.956 & 0.000 \\
5 & 0.769 & 0.714 & 0.673 & 0.417 & 0.920 \\
6 & 0.808 & 0.524 & 0.545 & 0.083 & 0.960 \\
8 & 0.385 & 0.181 & 0.218 & 0.250 & 0.832 \\
\hline
\end{tabular}

Note: I-II, II-III, III-IV, and IV-V in Table 3 represent the index boundary value of adjacent rock mass quality grades.

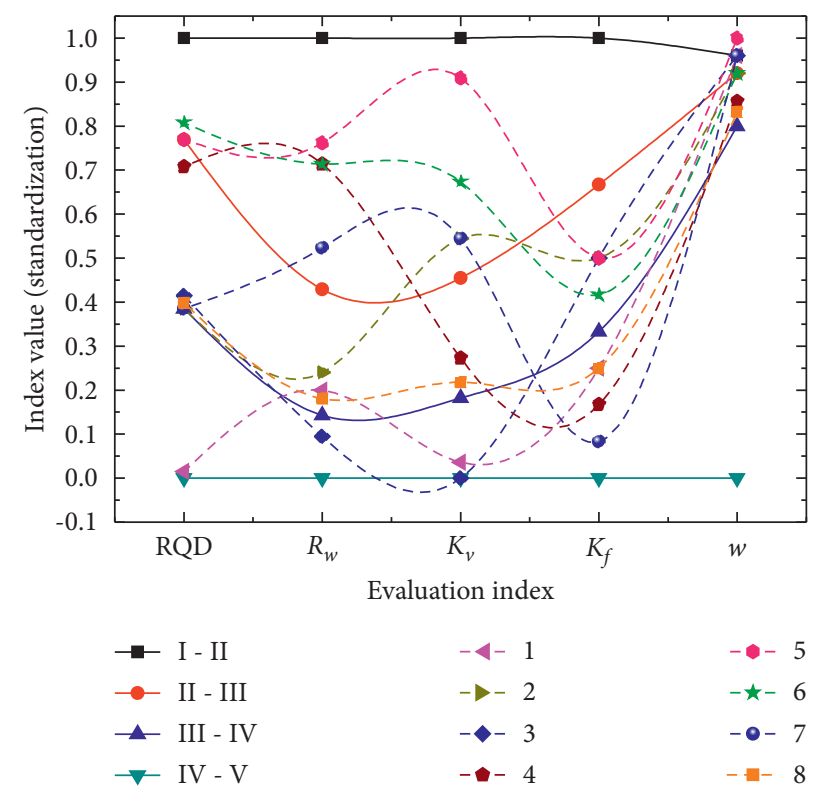

FIGURE 3: Analysis of grades of sample indexes. 


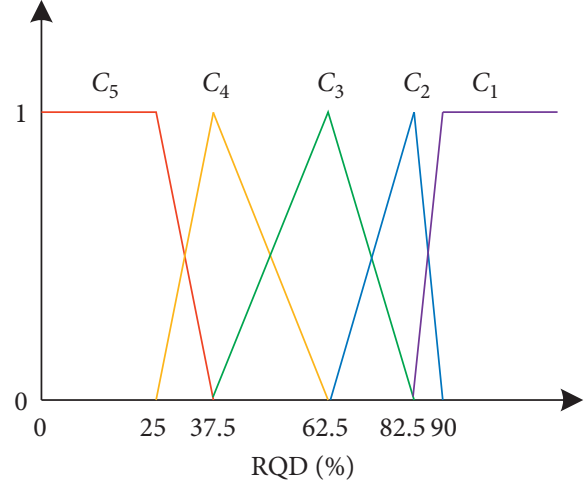

(a)

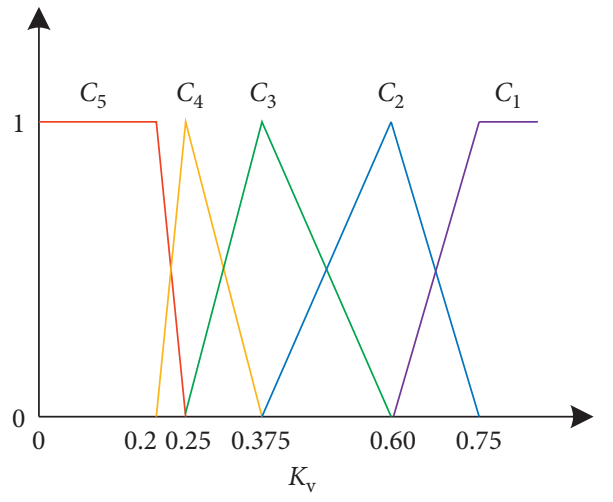

(c)

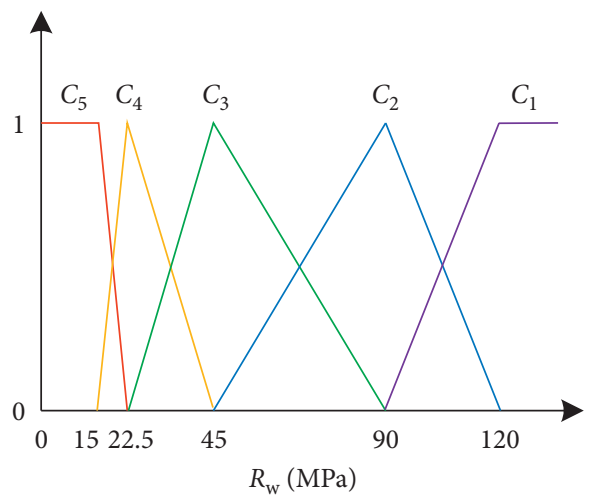

(b)

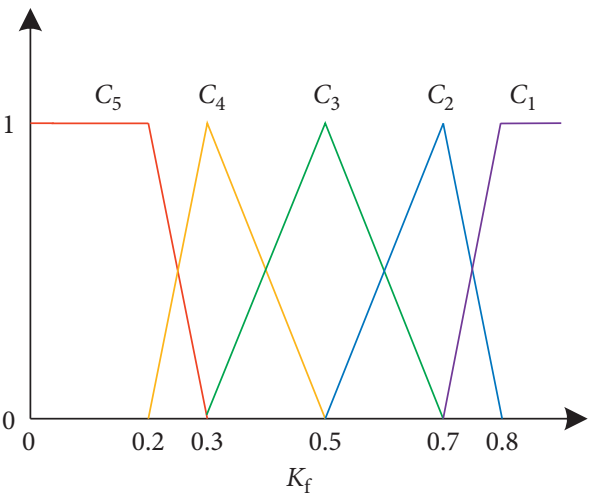

(d)

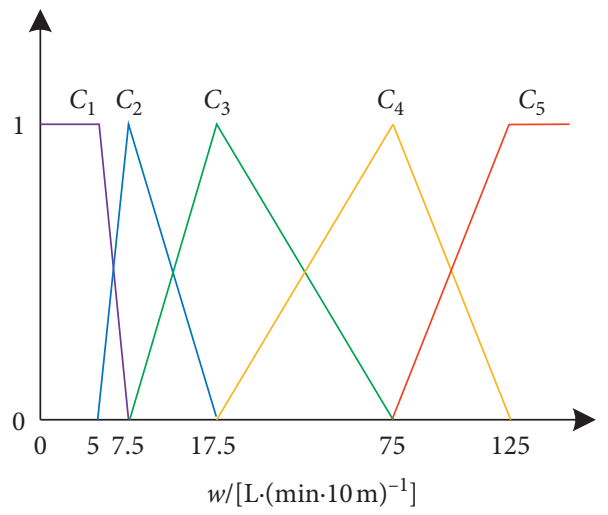

(e)

Figure 4: The single index measure function.

$$
\left(F_{1}\right)_{5 \times 5}=\left[\begin{array}{ccccc}
\langle 0.00,1.00\rangle & \langle 0.00,1.00\rangle & \langle 0.00,1.00\rangle & \langle 0.08,0.92\rangle & \langle 0.92,0.08\rangle \\
\langle 0.00,1.00\rangle & \langle 0.00,1.00\rangle & \langle 0.60,0.40\rangle & \langle 0.40,0.60\rangle & \langle 0.00,1.00\rangle \\
\langle 0.00,1.00\rangle & \langle 0.00,1.00\rangle & \langle 0.00,1.00\rangle & \langle 0.40,0.60\rangle & \langle 0.60,0.40\rangle \\
\langle 0.00,1.00\rangle & \langle 0.00,1.00\rangle & \langle 0.25,0.75\rangle & \langle 0.75,0.25\rangle & \langle 0.00,1.00\rangle \\
\langle 1.00,0.00\rangle & \langle 0.00,1.00\rangle & \langle 0.00,1.00\rangle & \langle 0.00,1.00\rangle & \langle 0.00,1.00\rangle
\end{array}\right]
$$

3.3.3. Multisource Weight Processing Based on IFS. Index weight has great influence on the result of rock mass quality evaluation. Because the subjective and objective weighting methods have their own advantages and disadvantages, it is difficult to select different weighting methods reasonably. Five commonly used subjective and objective weighting methods are considered, including rough set (RS) [41], grey weighting method (GWM) [43], entropy weight method 
(EWM) [44], analytic hierarchy process (AHP) [45], and pair-by-pair comparison (PPC) [46]. Among them, RS, GWM, and EWM are objective weighting methods, and AHP and PPC are subjective weighting methods. Through the investigation of those 5 weighting methods, the index weight can be determined in a reasonable range. The index weights obtained by the 5 weighting methods are shown in Table 4, and the weight distribution range is shown in Figure 5.

Obviously, the weights of indexes obtained by different weighting methods are different. In order to reduce the deficiency of single weighting method in the analysis of index importance, improve the rationality of index weight determination process and obtain the information contained in different weighting methods, according to IFS theory, IFS can evaluate an attribute in the form of interval value. Therefore, the range of index weight can be obtained by different weighting methods, and then, the index weight can be expressed as an interval value by using IFS.

Taking $R Q D$ as an example, the maximum and minimum values of the weight obtained by 5 weighting methods are 0.200 and 0.220 , respectively, so the range of the index weight is $0.200 \sim 0.220$, which is expressed as IFS-index weight $\langle 0.200,0.780\rangle$. Similarly, the weight range of other 4 indexes can be obtained.

The IFS-index weight vector of the 5 indexes is

$$
\begin{aligned}
W= & \left(\left\langle\rho_{q}, \tau_{q}\right\rangle\right)=(\langle 0.200,0.780\rangle,\langle 0.200,0.770\rangle, \\
& \langle 0.133,0.720\rangle,\langle 0.160,0.780\rangle,\langle 0.093,0.733\rangle) .
\end{aligned}
$$

3.3.4. Grade of Rock Mass Quality. According to equation (13), the weighted IFS-single index measure evaluation matrix is obtained from the IFS-single index measure evaluation matrix and IFS-index weight vector as follows:

$$
\left(\bar{F}_{1 j k}\right)_{5 \times 5}=\left[\begin{array}{ccccc}
\langle 0.000,1.000\rangle & \langle 0.000,1.000\rangle & \langle 0.000,1.000\rangle & \langle 0.016,0.982\rangle & \langle 0.183,0.798\rangle \\
\langle 0.000,1.000\rangle & \langle 0.000,1.000\rangle & \langle 0.120,0.862\rangle & \langle 0.080,0.908\rangle & \langle 0.000,1.000\rangle \\
\langle 0.000,1.000\rangle & \langle 0.000,1.000\rangle & \langle 0.000,1.000\rangle & \langle 0.053,0.888\rangle & \langle 0.079,0.832\rangle \\
\langle 0.000,1.000\rangle & \langle 0.000,1.000\rangle & \langle 0.040,0.945\rangle & \langle 0.120,0.835\rangle & \langle 0.000,1.000\rangle \\
\langle 0.093,0.733\rangle & \langle 0.000,1.000\rangle & \langle 0.000,1.000\rangle & \langle 0.000,1.000\rangle & \langle 0.000,1.000\rangle
\end{array}\right] .
$$

According to equation (12), the comprehensive mean values corresponding to the 5 rock mass quality grades of sample 1 are obtained from weighted IFS-single index measure evaluation matrix as follows:

$$
\begin{aligned}
& S_{11}=\sum_{q=1}^{Q} \bar{F}_{1 q 1}=\langle 0.093,0.733\rangle, \\
& S_{12}=\sum_{q=1}^{Q} \bar{F}_{1 q 2}=\langle 0.000,1.000\rangle, \\
& S_{13}=\sum_{q=1}^{Q} \bar{F}_{1 q 3}=\langle 0.155,0.815\rangle, \\
& S_{14}=\sum_{q=1}^{Q} \bar{F}_{1 q 4}=\langle 0.246,0.661\rangle, \\
& S_{15}=\sum_{q=1}^{Q} \bar{F}_{1 q 5}=\langle 0.247,0.664\rangle .
\end{aligned}
$$


TABLE 4: Index weight determined by subjective and objective weighting methods.

\begin{tabular}{lccccc}
\hline Weighting method & RQD $(\%)$ & $R_{\mathrm{W}}(\mathrm{MPa})$ & $K_{\mathrm{v}}$ & $K_{\mathrm{f}}$ & $w\left[\mathrm{~L} \cdot(\mathrm{min} \cdot 10 \mathrm{~m})^{-1}\right]$ \\
\hline RS & 0.200 & 0.200 & 0.133 & 0.200 & 0.267 \\
GWM & 0.200 & 0.200 & 0.200 & 0.200 & 0.200 \\
EWM & 0.200 & 0.223 & 0.280 & 0.204 & 0.093 \\
AHP & 0.220 & 0.200 & 0.180 & 0.220 & 0.180 \\
PPC & 0.200 & 0.230 & 0.200 & 0.160 & 0.210 \\
\hline
\end{tabular}

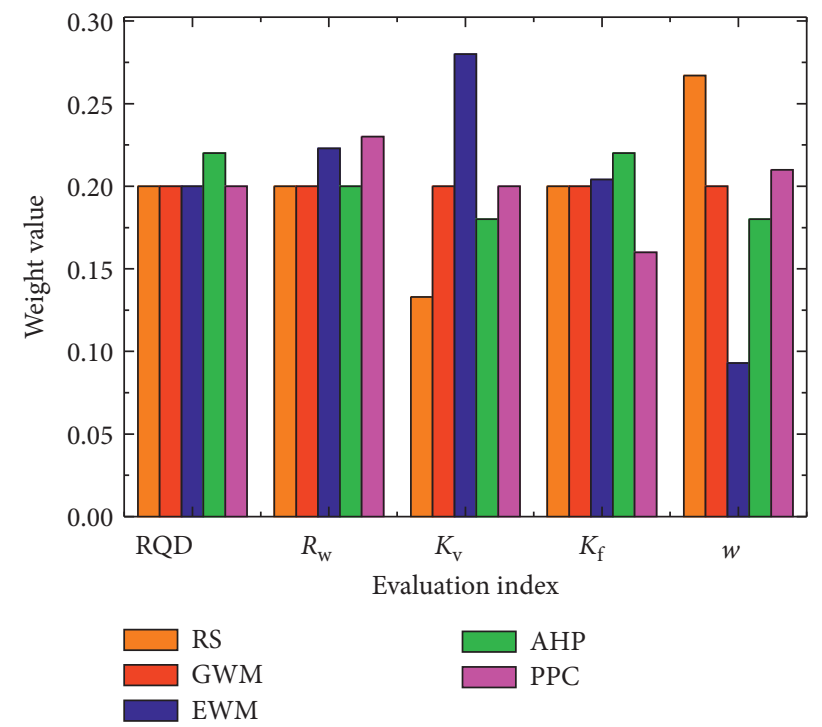

FIgURE 5: Distribution of index weight.

Therefore, the corresponding scores of 5 rock mass quality grades of sample 1 are as follows:

$$
M_{1}=\left\{\begin{array}{l}
M_{1}\left(S_{11}\right) \\
M_{1}\left(S_{12}\right) \\
M_{1}\left(S_{13}\right) \\
M_{1}\left(S_{14}\right) \\
M_{1}\left(S_{15}\right)
\end{array}\right\}=\left\{\begin{array}{l}
0.093-0.733 \\
0.000-1.000 \\
0.155-0.815 \\
0.246-0.661 \\
0.247-0.664
\end{array}\right\}=\left\{\begin{array}{l}
-0.640 \\
-1.000 \\
-0.660 \\
-0.415 \\
-0.417
\end{array}\right\} .
$$

According to the scores of sample 1 above, it can be seen that the score of grade IV is the highest, so its result of rock mass quality evaluation is IV, which belongs to instability rock mass, and corresponding measures should be taken in time for prevention and control when necessary.

\subsection{Results and Analysis}

3.4.1. Analysis of Results. The established model for evaluation of rock mass quality is applied to other samples. At the same time, the evaluation results are compared with other 4 effective models for rock mass quality evaluation, including RS-TOPSIS [41], CPM [47], ANN [42], and SVM [48]. The comparison results are shown in Table 5.

From the comparison of the evaluation results in Table 5, it can be seen that the evaluation results of the established model are consistent with those of other 4 models, indicating that the built model based on UM-IFS is reliable and its evaluation results meet the expectations. Compared with these 4 models, RS-TOPSIS and CPM are excessively dependent on sample data, and their evaluation process is entirely dependent on data quality; prediction results of ANN and SVM, as machine learning algorithms, are unstable. In this work, the theory of UM is used to determine the membership of the index, and a fuzzy information expression method based on UM-IFS is proposed to solve the problem of fuzzy processing of index and weight in rock quality evaluation. This method effectively reduces the influence of sample quantity and quality on the model for rock mass quality evaluation and provides a new idea for the study of rock mass quality evaluation.

3.4.2. Fuzzy Analysis of Index Weight. The index weight has a great influence and fuzziness in the evaluation of rock mass quality. Therefore, the fuzzy analysis of index weight is of great significance.

Take $R Q D$ of sample 1 as an example and analyze its fuzziness. According to the comprehensive mean value $S_{1 i}$ of the sample 1 , if other conditions remain unchanged, the weight $w_{1}=\left\langle\rho_{1}, \tau_{1}\right\rangle=\langle 0.200,0.780\rangle$ of $R Q D$ is changed to $w_{1}^{\prime}=\left\langle\rho_{1}+\Delta \rho_{1}, \tau_{1}+\Delta \tau_{1}>=<0.200+\Delta \rho_{1}, 0.780+\Delta \tau_{1}>\right.$, and the comprehensive mean value $S_{14}>S_{15}>S_{11}>S_{13}>S_{12}$ of sample 1 remains unchanged, so as to determine the range of 
TABLE 5: Comparison of results of rock mass quality evaluation.

\begin{tabular}{|c|c|c|c|c|c|}
\hline Sample & This work & RS-TOPSIS & CPM & ANN & SVM \\
\hline 1 & IV & IV & IV & IV & IV \\
\hline 2 & III & III & III & III & III \\
\hline 3 & III & III & III & III & III \\
\hline 4 & III & III & III & III & III \\
\hline 5 & II & II & II & II & II \\
\hline 6 & II & II & II & II & II \\
\hline 7 & III & III & III & III & III \\
\hline 8 & III & III & III & III & III \\
\hline
\end{tabular}

TABLE 6: Fuzzy analysis of index weight.

\begin{tabular}{|c|c|c|}
\hline Index & The range of $\Delta \rho$ and $\Delta \tau$ & Fuzzy value \\
\hline$R Q D$ & $\left\{\begin{array}{l}-0.002+0.785 \Delta \rho_{1}-0.712 \Delta \tau_{1}<0 \\
-0.222-0.847 \Delta \rho_{1}+0.765 \Delta \tau_{1}<0 \\
-0.980 \leq \Delta \rho_{1}+\Delta \tau_{1} \leq 0.020 \\
-0.200 \leq \Delta \rho_{1} \leq 0.020 \\
-0.780 \leq \Delta \tau_{1} \leq 0.020\end{array}\right.$ & $\zeta_{11}=0.179$ \\
\hline$R_{\mathrm{W}}$ & $\left\{\begin{array}{l}-0.021+0.576 \Delta \rho_{2}-0.567 \Delta \tau_{2}<0 \\
-0.340-0.576 \Delta \rho_{2}+0.567 \Delta \tau_{2}<0 \\
-0.002-0.109 \Delta \rho_{2}+0.291 \Delta \tau_{2}<0 \\
-0.970 \leq \Delta \rho_{2}+\Delta \tau_{2} \leq 0.030 \\
-0.200 \leq \Delta \rho_{2} \leq 0.030 \\
-0.770 \leq \Delta \tau_{2} \leq 0.030\end{array}\right.$ & $\zeta_{12}=0.138$ \\
\hline$K_{\mathrm{v}}$ & $\left\{\begin{array}{l}-0.002-0.198 \Delta \rho_{3}-0.181 \Delta \tau_{3}<0 \\
-0.222-0.121 \Delta \rho_{3}+0.478 \Delta \tau_{3}<0 \\
-0.853 \leq \Delta \rho_{3}+\Delta \tau_{3} \leq 0.146 \\
-0.133 \leq \Delta \rho_{3} \leq 0.146 \\
-0.720 \leq \Delta \tau_{3} \leq 0.146\end{array}\right.$ & $\zeta_{13}=0.152$ \\
\hline$K_{\mathrm{f}}$ & $\left\{\begin{array}{l}-0.002-0.643 \Delta \rho_{4}+0.593 \Delta \tau_{4}<0 \\
-0.340-0.220 \Delta \rho_{4}+0.215 \Delta \tau_{4}<0 \\
-0.021+0.220 \Delta \rho_{4}-0.215 \Delta \tau_{4}<0 \\
-0.940 \leq \Delta \rho_{4}+\Delta \tau_{4} \leq 0.060 \\
-0.160 \leq \Delta \rho_{4} \leq 0.060 \\
-0.780 \leq \Delta \tau_{4} \leq 0.060\end{array}\right.$ & $\zeta_{14}=0.125$ \\
\hline$w$ & $\left\{\begin{array}{l}\Delta \rho_{5}-\Delta \tau_{5}-0.223<0 \\
-0.020-\Delta \rho_{5}+\Delta \tau_{5}<0 \\
-0.826 \leq \Delta \rho_{5}+\Delta \tau_{5} \leq 0.174 \\
-0.093 \leq \Delta \rho_{5} \leq 0.174 \\
-0.733 \leq \Delta \tau_{5} \leq 0.174\end{array}\right.$ & $\zeta_{15}=0.323$ \\
\hline
\end{tabular}

weight changes of RQD. Then, the IFS-index weight of RQD of sample 1 should meet the following conditions:

$$
\left\{\begin{array}{l}
M_{1}^{\prime}\left(S_{14}\right)>M_{1}^{\prime}\left(S_{15}\right), \\
M_{1}^{\prime}\left(S_{15}\right)>M_{1}^{\prime}\left(S_{11}\right), \\
M_{1}^{\prime}\left(S_{11}\right)>M_{1}^{\prime}\left(S_{13}\right), \\
M_{1}^{\prime}\left(S_{13}\right)>M_{1}^{\prime}\left(S_{12}\right), \\
0 \leq \rho_{q}+\Delta \rho_{q}+\tau_{q}+\Delta \tau_{q} \leq 1, \\
0 \leq \rho_{q}+\Delta \rho_{q} \leq 1-\tau_{q}, \\
0 \leq \tau_{q}+\Delta \tau_{q} \leq 1-\rho_{q} .
\end{array}\right.
$$

The range of $\Delta \rho_{1}$ and $\Delta \tau_{1}$ obtained from the above equations is the range of weight changes of RQD of sample 1. Similarly, the range of weight changes of $R_{\mathrm{W}}, K_{\mathrm{v}}, K_{\mathrm{f}}$, and $w$ can be obtained. The range of weight changes of 5 indexes in sample 1 is shown in Table 6 and Figure 6.

The filling part in Figure 6 is the range of $\Delta \rho$ and $\Delta \tau$ of the index weight when the results of rock mass quality evaluation of sample 1 remain unchanged. The pink filled area is the range determined by inequality group (14), and the red and pink filled area is the range determined by the last 3 inequalities in inequality group (14). The smaller the proportion of pink area in the total area is, the less fuzzy the index weight is. According to equation (15), the fuzzy values of each index weight are obtained:

$$
\zeta_{14}=0.125<\zeta_{12}=0.138<\zeta_{13}=0.152<\zeta_{11}=0.179<\zeta_{15}=0.323 \text {. }
$$

Therefore, for the 5 indexes of rock mass quality evaluation, the influence of weight change of $K_{\mathrm{f}}, R_{\mathrm{W}}, K_{\mathrm{v}}, R Q D$, 

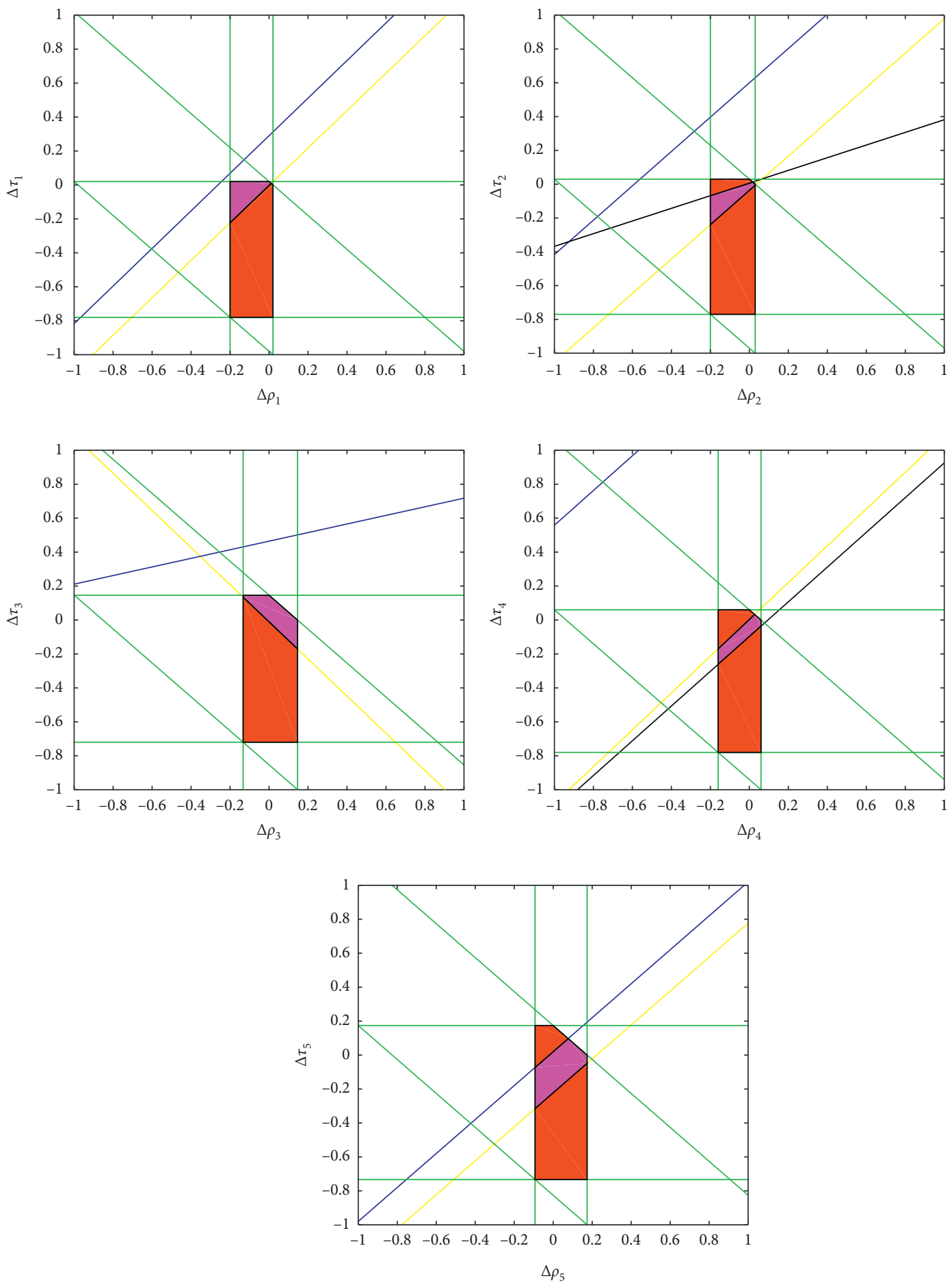

- The line determined by the last 3 inequalities in inequality group (14)

= The line determined by the first 2 inequalities in inequality group (14)

The range determined by the last 3 inequalities in inequality group (14)

The range determined by inequality group (14)

FIgURE 6: The range of index weight change.

and $w$ on the result of rock mass quality evaluation gradually decreases.

The relationship between IFS-index weight of index and its fuzzy value, including membership, nonmembership, hesitancy degree, and the sum of membership and hesitancy degree, are analyzed. The analysis results are shown in Table 7 and Figure 7.

From Table 7 and Figure 7, there is no obvious regular relationship between the IFS-index weight of index and its fuzzy value; that is, the fuzziness of index weight is not 
TABLe 7: Analysis of fuzzy value and weight.

\begin{tabular}{lccccc}
\hline & RQD (\%) & $R_{\mathrm{W}}(\mathrm{MPa})$ & $K_{\mathrm{v}}$ & $K_{\mathrm{f}}$ & $w\left[\mathrm{~L} \cdot(\mathrm{min} \cdot 10 \mathrm{~m})^{-1}\right]$ \\
\hline Membership & 0.200 & 0.200 & 0.133 & 0.160 & 0.093 \\
Nonmembership & 0.780 & 0.770 & 0.720 & 0.780 & 0.733 \\
Hesitation degree & 0.020 & 0.030 & 0.147 & 0.060 & 0.174 \\
Membership + hesitation degree & 0.22 & 0.23 & 0.28 & 0.22 & 0.267 \\
Fuzzy value & 0.179 & 0.138 & 0.152 & 0.125 & 0.323 \\
\hline
\end{tabular}

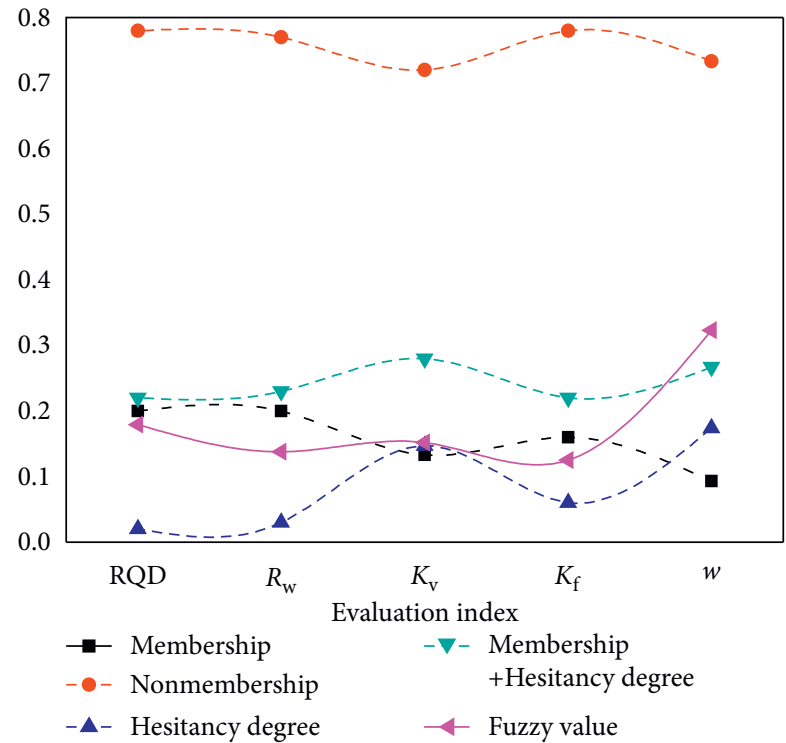

Figure 7: The relationship between weight and fuzzy value.

related to the index weight and its hesitancy degree. With the continuous accumulation of analysis samples, it can gradually reduce the range of index weight fluctuation and improve the reliability of index weight, which is of theoretical significance for the analysis of the importance of index and the improvement of the accuracy of model for rock mass quality evaluation.

\section{Conclusions}

The evaluation of rock mass quality is affected by many indexes, which are fuzzy, uncertain, and complex. Therefore, it is necessary to fully consider the fuzziness of these indexes in the study of rock mass quality evaluation. In addition, the influence degree of each index on rock mass quality evaluation is different. The importance of these indexes is analyzed to provide theoretical basis for reasonable evaluation and analysis of rock mass quality.

The fuzzy information expression method of rock mass quality evaluation index based on the UM-IFS improves the membership calculation of rock mass quality evaluation index value and optimizes the expression of index fuzziness. The evaluation of rock mass quality contains a lot of fuzzy information. The membership of index of rock mass quality evaluation is determined by UM theory, and the index measure value determined by single index measure function is expressed by IFS. It extends the fuzzy expression method of index value and improves the ability of model for rock mass quality evaluation to deal with unascertained information of index.

The index weighting method based on IFS reasonably deals with the problem that different weighting methods are difficult to choose. Index weight is one of the important factors that affect the evaluation results. Through the use of a variety of subjective and objective weighting methods to calculate the index weight, the multisource weight of the rock quality evaluation index is determined in a certain range, and finally, the IFS-index weight is obtained according to the IFS. By combining UM with IFS, a model for evaluation of rock mass quality based on UM-IFS is established to reduce the impact of sample quantity and quality on the evaluation model. The established model is verified with other 4 effective models for rock mass quality evaluation that the established model is scientific and reasonable with reliable results.

The fuzzy analysis of index of rock mass quality evaluation makes up for the deficiency of fuzzy analysis of indexes in previous evaluation models. The fuzzy analysis of index weight can study the influence of the change of index weight on the evaluation results. The results show that the fuzziness of index weight has no obvious relationship with its value. Through the accumulation of fuzzy analysis of index weight, it can gradually reduce the range of index weight and the fuzziness of index weight, which has theoretical significance for the study on the importance of index of rock mass quality evaluation.

The limitations of our work are also obvious due to the model construction. First, the established model needs to calculate each sample one by one, which is not suitable for group decision-making. Second, considering the analysis result, due to the limitation of case, there is lack of in-depth study on qualitative index. It still needs more detailed works on the fuzzy processing of index value to highlight the practicability of the method. Finally, the process of fuzzy analysis of index weight is complex. So, we have to further improve the evaluation efficiency and consider the applicability of the actual project.

Regarding the above limitations and the fact that rock mass quality is the foundation of geotechnical engineering design and construction, it needs further study. As to future work, we will research the linguistic fuzzy set and group decision-making, including the linguistic interval-valued IFS [49] and hesitant fuzzy linguistic term set possibility distributions [50], which will enrich the expression methods of qualitative indexes in rock mass quality evaluation and improve the evaluation efficiency; it would provide qualitative fuzzy evaluation information that is more close to 
human's cognitive process. In addition, future work may introduce various uncertainty methods to enrich the IFS, so as to better deal with the fuzzy information in the rock quality evaluation, especially the index weight. After that, it could finally provide great references for relevant researchers and help to make scientific and efficient decisions.

\section{Data Availability}

The data used to support the findings of this study are included within the article.

\section{Conflicts of Interest}

The authors declare that they have no conflicts of interest.

\section{Acknowledgments}

This study was supported by the Science and Technology Project of Education Department of Jiangxi Province (Grant no. GJJ170466), the Doctoral Starting up Foundation of East China University of Technology (Grant no. DHBK2016125), and Key Laboratory for Digital Land and Resources of Jiangxi Province, East China University of Technology (Grant no. DLLJ201706).

\section{References}

[1] F. Ji, Y. Shi, R. Li, C. Zhou, N. Zhang, and J. Gao, "Modified Q-index for prediction of rock mass quality around a tunnel excavated with a tunnel boring machine (TBM)," Bulletin of Engineering Geology and the Environment, vol. 78, no. 5, pp. 3755-3766, 2019.

[2] W. Pytel and B. Pałac-Walko, "Geomechanical safety assessment for transversely isotropic rock mass subjected to deep mining operations," Canadian Geotechnical Journal, vol. 52, no. 10, pp. 1477-1489, 2015.

[3] M. M. Protodyakonov, "Methods of studying the strength of rocks, used in the U.S.S.R," in Mining Research, Mining Institute USSR Academy of Sciences, pp. 649-668, Moscow, Russia, 1962.

[4] L. Zhang, "Determination and applications of rock quality designation (RQD)," Journal of Rock Mechanics and Geotechnical Engineering, vol. 8, no. 3, pp. 389-397, 2016.

[5] E. H. Skinner, "A ground support prediction concept: the rock structure rating (rsr) model," Rock Classification Systems for Engineering Purposes, West Conshohocken, PA, USA, 1988.

[6] J. K. Hamidi, K. Shahriar, B. Rezai, and J. Rostami, "Performance prediction of hard rock TBM using Rock Mass Rating (RMR) system," Tunnelling \& Underground Space Technology Incorporating Trenchless Technology Research, vol. 25, no. 4, pp. 333-345, 2010.

[7] S. Y. Choi and H. D. Park, "Comparison among different criteria of RMR and Q-system for rock mass classification for tunnelling in Korea," Tunnelling and Underground Space Technology, vol. 17, no. 4, pp. 391-401, 2002.

[8] D. Z. Gu and D. C. Huang, "Classification of rock mass structure and determination of its quality coefficient," Hydrogeology and Engineering Geology, vol. 2, pp. 10-15, 1979.

[9] D. Y. Sun, Z. Y. Chen, B. D. Hui, and Y. C. Cao, "Modifications to the RMR-SMR system for slope stability evaluation," Chinese Journal of Rock Mechanics and Engineering, vol. 16, no. 4, p. 297, 1997.
[10] M. Vavro, K. Souček, L. Staš et al., "Application of alternative methods for determination of rock quality designation (RQD) index: a case study from the Rožná I uranium mine, Strážek Moldanubicum, Bohemian Massif, Czech Republic," Canadian Geotechnical Journal, vol. 52, no. 10, pp. 1466-1476, 2015.

[11] H. Xu, J. Liu, L. Wang, B. Yang, and H. Yang, "The weakening effect of hydrostatic pressure on rock mass of different lithology," Environmental Earth Sciences, vol. 74, no. 3, pp. 2489-2497, 2015.

[12] J. Shang, L. J. West, S. R. Hencher, and Z. Zhao, "Geological discontinuity persistence: implications and quantification," Engineering Geology, vol. 241, pp. 41-54, 2018.

[13] S. C. Li, X. D. Feng, and S. C. Li, "Numerical model for the zonal disintegration of the rock mass around deep underground workings," Theoretical and Applied Fracture Mechanics, vol. 67-68, pp. 65-73, 2013.

[14] C. Y. Chen and G. R. Wang, "Discussion on the interrelation of various rock mass quality classification systems at home and abroad," Chinese Journal of Rock Mechanics and Engineering, vol. 21, no. 12, pp. 1894-1900, 2002.

[15] M. Behnia and M. C. Seifabad, "Stability analysis and optimization of the support system of an underground powerhouse cavern considering rock mass variability," Environmental Earth Sciences, vol. 77, no. 18, p. 645, 2018.

[16] H. Fattahi, M. A. E. Farsangi, S. Shojaee, and H. Mansouri, "Selection of a suitable method for the assessment of excavation damage zone using fuzzy AHP in Aba Saleh Almahdi tunnel, Iran," Arabian Journal of Geosciences, vol. 8, no. 5, pp. 2863-2877, 2015.

[17] M. Rezaei and M. Monjezi, “An intelligent approach to predict unconfined compressive strength of rock surrounding access tunnels in longwall coal mining," Neural Computing and Applications, vol. 24, no. 1, pp. 233-241, 2014.

[18] L. Z. Wu, S. H. Li, M. Zhang, and L. M. Zhang, "A new method for classifying rock mass quality based on MCS and TOPSIS," Environmental Earth Sciences, vol. 78, no. 6, 2019.

[19] G. L. Liang, W. Y. Xu, and X. L. Tan, "Application of extension theory based on entropy weight to rock quality evaluation," Rock and Soil Mechanics, vol. 31, no. 2, pp. 535-540, 2010.

[20] Y. P. Yao, X. B. Li, F. Q. Gong, and K. Peng, "Application of weighted mahalanobis distance discriminant analysis method to classification of rock mass quality," Chinese Journal of Rock Mechanics and Engineering, vol. 29, no. s2, pp. 4119-4123, 2010.

[21] M. N. Bagde, A. K. Raina, A. K. Chakraborty, and J. L. Jethwa, "Rock mass characterization by fractal dimension," Engineering Geology, vol. 63, no. 1-2, pp. 141-155, 2002.

[22] K. T. Atanassov, "Intuitionistic fuzzy sets," Fuzzy Sets and Systems, vol. 20, no. 1, pp. 87-96, 1986.

[23] S. P. Wan and J. Y. Dong, Decision Making Theories and Methods Based on Interval-Valued Intuitionistic fuzzy Set, Springer, Singapore, 2020.

[24] H. Garg, "A new generalized improved score function of interval-valued intuitionistic fuzzy sets and applications in expert systems," Applied Soft Computing, vol. 38, pp. 988-999, 2016.

[25] H. Garg and G. Kaur, "Cubic intuitionistic fuzzy sets and its fundamental properties," Journal of Multiple-Valued Logic and Soft Computing, vol. 33, no. 6, pp. 507-537, 2019.

[26] Y. Yang, Z.-S. Chen, Y.-H. Chen, and K.-S. Chin, "Intervalvalued pythagorean fuzzy frank power aggregation operators based on an isomorphic frank dual triple," International Journal of Computational Intelligence Systems, vol. 11, no. 1, pp. 1091-1110, 2018. 
[27] R. R. Yager, "Pythagorean membership grades in multicriteria decision making," IEEE Transactions On Fuzzy Systems, vol. 22, no. 4, pp. 958-965, 2014.

[28] Z.-S. Chen, K.-S. Chin, Y.-L. Li, and Y. Yang, "Proportional hesitant fuzzy linguistic term set for multiple criteria group decision making," Information Sciences, vol. 357, pp. 61-87, 2016.

[29] Z.-S. Chen, Y. Yang, X.-J. Wang, K.-S. Chin, and K.-L. Tsui, "Fostering linguistic decision-making under uncertainty: a proportional interval type-2 hesitant fuzzy TOPSIS approach based on Hamacher aggregation operators and andness optimization models," Information Sciences, vol. 500, pp. 229258, 2019.

[30] S. C. Li, J. Wu, Z. H. Xu, and L. P. Li, "Unascertained measure model of water and mud inrush risk evaluation in karst tunnels and its engineering application," KSCE Journal of Civil Engineering, vol. 21, no. 4, pp. 1170-1182, 2017.

[31] K. T. Atanassov, Intuitionistic fuzzy Sets, Springer, Heidelberg, Germany, 1999.

[32] L. A. Zadeh, "Fuzzy sets," Information and Control, vol. 8, no. 3, pp. 338-353, 1965.

[33] G. Wang, "Unascertained information and its mathematical treatment," Journal of Harbin University of Civil Engineering and Architecture, vol. 23, no. 4, pp. 1-9, 1990.

[34] K. D. Liu, H. Q. Wu, N. P. Wang, H. J. Li, and S. Y. Liu, Unascertained Mathematics, Huazhong University of Science \& Technology Press, Wuhan, China, 1997.

[35] K. Liu, Mathematical Processing and Application of Uncertainty Information, Science Press, Beijing, China, 1999.

[36] W. Qiang, D. K. Zhao, W. Yang, J. J. Shen, W. P. Mu, and H. L. Liu, "Method for assessing coal-floor water-inrush risk based on the variable-weight model and unascertained measure theory," Hydrogeology Journal, vol. 25, no. 10, pp. 1-15, 2017.

[37] S. J. Luo, "Introduction of Guangzhou pumped storage power plant," Water Power, vol. 10, pp. 3-7, 1990.

[38] H. H. Einstein, D. Veneziano, G. B. Baecher, and K. J. O’Reilly, "The effect of discontinuity persistence on rock slope stability," International Journal of Rock Mechanics and Mining Sciences \& Geomechanics Abstracts, vol. 20, no. 5, pp. 227236, 1983.

[39] J. Shang, S. R. Hencher, L. J. West, and K. Handley, "Forensic excavation of rock masses: a technique to investigate discontinuity persistence," Rock Mechanics and Rock Engineering, vol. 50, no. 11, pp. 2911-2928, 2017.

[40] Y. F. Liu and B. X. Gong, "Analyses of ground stress field in underground excavation of Guangzhou pumped storage power station," Journal of Yangtze River Scientific Research Institute, vol. 7, no. 4, pp. 45-53, 1990.

[41] J. H. Hu, J. L. Shang, and T. Lei, "Rock mass quality evaluation of underground engineering based on RS-TOPSIS method," Journal of Central South University (Science and Technology), vol. 43, no. 11, pp. 4412-4419, 2012.

[42] G. K. Cai, Study of the BP Neural Network on the Stability Classification of Surrounding Rocks, Hohai University, Nanjing, China, 2001.

[43] Y. G. Feng, "Application of grey optimal theory model in the stability classification of adjoining rock of underground construction," Chinese Journal of Geotechnical Engineering, vol. 3, pp. 62-66, 1996.

[44] R. D. Huang, K. Liu, H. X. Gong, and H. F. Wang, "Stability assessment of surrounding rocks based on entropy weight and ideal point methods," Science \& Technology Review, vol. 20, pp. 64-68, 2014.
[45] H. T. Wang and S. P. Wang, "Surrounding rock classification study based on set pair analytic hierarchy process," Journal of Dalian University, vol. 5, pp. 88-91, 2015.

[46] J. W. Zhang, Mining System Engineering, China University of Mining and Technology press, Xuzhou, China, 2015.

[47] F. Q. Gong, X. B. Li, and K. Gao, "Catastrophe progression method for stability classification of underground engineering surrounding rock," Journal of Central South University (Science and Technology), vol. 5, pp. 1081-1086, 2008.

[48] Y. B. Lai, Application and Study of Support Vector Machine in the Underground Engineering, Shandong University of Science and Technology, Qingdao, China, 2004.

[49] H. Garg and K. Kumar, "Linguistic interval-valued Atanassov intuitionistic fuzzy sets and their applications to group decision making problems," IEEE Transactions On Fuzzy Systems, vol. 27, no. 12, pp. 2302-2311, 2019.

[50] Z.-S. Chen, L. Martínez, K.-S. Chin, and K.-L. Tsui, “Twostage aggregation paradigm for HFLTS possibility distributions: a hierarchical clustering perspective," Expert Systems with Applications, vol. 104, pp. 43-66, 2018. 